\title{
Pesquisas prioritárias sobre doença de Chagas na Amazonia: agenda de curto-médio prazo*
}

\author{
Priority researches on Chagas' disease in the Amazonia Region: \\ a short-medium term schedule
}

\begin{abstract}
João Carlos Pinto Dias', Márcio Costa Vinhaes², Antônio Carlos Silveira ${ }^{3}$, Christopher John Schofield ${ }^{4}$, Bernardo Cardoso ${ }^{5}$ e José Rodrigues Coura ${ }^{1}$
\end{abstract}

Na programação da $V$ Jornada de Diagnóstico, Tratamento e Controle de Doenças Tropicais do Baixo Amazonas, em face ao crescente interesse que a doença de Chagas vem despertando na região, foi levada a cabo uma extensa e rica reunião científica sobre os diversos aspectos da tripanossomíase americana na Amazônia. Como objetivo central destas atividades, buscou-se proporcionar informações atualizadas e elevar o conhecimento técnico, despertando para a pesquisa e favorecendo o intercâmbio científico entre os diferentes profissionais, setores e instituições envolvidos com o tema. De modo geral, os relatos reiteraram a existência de uma enzootia peculiar e com particularidades sub-regionais em toda a Amazônia, com ampla dispersão de vetores silvestres e do agente etiológico, este geralmente classificado como do zimodema Z1 (Miles). Os ciclos enzoóticos envolvem diversos subsistemas ecológicos, ainda mal estabelecidos. Os vetores mais presentes pertencem ao gênero Rhodnius, com baixíssimas taxas de colonização domiciliar na região, até o presente. Ciclos particulares e domiciliação incipiente de Panstrongylus geniculatus (Pará) e Triatoma maculata (Roraima) têm sido observados, sem indicação de significativa transmissão vetorial às populações humanas adjacentes. Não há registro de domiciliação de vetores procedentes de outras regiões endêmicas que ao longo dos últimos 60 anos vêm proporcionando a colonização humana da Amazônia. A doença de Chagas humana ocorre difusamente na região, à custa de imigração de infectados e de alguns focos de transmissão local, ainda não bem estudados. Neste sentido, registra-se um foco particular transmissão no Alto Rio Negro, ligado a $R$. brethesi em áreas de exploração da piaçava e uma série de episódios esparsos de microepidemias familiares de doença aguda no Pará, provavelmente devidos a contaminação oral. Não se registram dados importantes de morbidade, especialmente da doença crônica, havendo indicações de muito baixa mortalidade. Com vistas ao estabelecimento do real tamanho do problema e suas peculiaridades, especialmente estabelecendo-se suas perspectivas de vigilância e controle, designou-se uma pequena Comissão para destacar, do bojo das discussões uma listagem preliminar de pesquisas prioritárias, que a Revista da SBMT traz a público, naturalmente na expectativa de novos temas, críticas e sugestões.

Pauta de pesquisas prioritárias. Vetores: distribuição e mapeamento das espécies encontradas por micro regiões homogêneas estabelecidas por satélite. Estudo de indices de infecção natural por Trypanosoma cruzi e $T$. rangeli. Indices de colonização e perfil de fonte alimentar. Estudos finos de localização dos vetores no intra e peridomicílio. Estabelecimento de suscetibilidade dos vetores amazônicos a diferentes cepas de T. cruzi, especialmente do tipo Z2. Estudos filogenéticos do gênero Rhodnius. Estudos particulares de eventuais colonizações detectadas (área, sazonalidade, entorno ecológico, condicionamentos sociais, etc.), com destaque para $T$. maculata e P. geniculatus (com domiciliação incipiente) e $R$. brethesi, (com antecedentes de transmissão no Alto Rio Negro, mas sem colonização registrada). Monitoramento sistematizado e mapeamento das áreas de dispersão atual destas espécies por cinco anos, para avaliação de tendências, cuidando-se eticamente de não permitir colonização. Aprimoramento de métodos de captura no intra e no peridomicílio, assim como em ecótopos silvestres. Avaliação objetiva do conhecimento sobre vetores de populações locais, nativas ou imigradas, com destaque para povos indígenas.

Reservatórios: pesquisa sistematizada e dirigida, em regiões de ocorrência de vetores e casos

\footnotetext{
* Elaborada no I Encontro Técnico de Doença de Chagas no Baixo Amazonas realizado em Santarém, Pará, no período de 23 a 28 de julho de 2001. 1. Centro de Pesquisas René Rachou da Fundação Oswaldo Cruz; 2. Fundação Nacional de Saúde; 3. Assessor Temporário da OPS/Brasil; 4. London School of Tropical Medicine and Hygiene e Rede ECLAT; 5. Universidade Federal do Pará.

Endereço para correspondência: Dr. João Carlos Pinto Dias. Centro de Pesquisas René Rachou/FIOCRUZ. Av. Augusto de Lima 1715, 30190-002 Belo Horizonte, MG, Brasil.

Tel: $55313295-3566$

e-mail: jcpdias@cpqrr.fiocruz.br

Recebido para publicação em 16/8/2001
} 
humanos, com vistas à detecção de infeção natural. Tentar estabelecer correlações de infeção/morbidade. Rastreamento de animais parasitados (método de Barata e similares) para estudo das características dos ecótopos silvestres e detecção de vetores.

Agente etiológico: definição das populações detectadas em diversos hospedeiros (vetores, humanos, reservatórios não humanos), com tipologia enzimática e análise de filogênese. Correlação com os vetores locais (afinidade, distribuição). Potencial patogênico para modelos experimentais. Co-infecção com $T$. rangeli.

Doença de Chagas humana: complementação do inquérito sorológico já previsto (menores de 5 anos), ampliando-se para outras faixas etárias. Definição estrita da autoctonia dos casos detectados. Definição dos mecanismos de transmissão. Estudo particular de gestantes infectadas e de filhos de mães chagásicas, para avaliação de transmissão congênita. Aprofundamento da avaliação dos bancos de sangue, com vistas à determinação de doadores e candidatos infectados, bem como para a análise da qualidade do sangue transfundido. Aprofundamento do estudo das microepidemias familiares com vistas ao estabelecimento de todas as fontes e mecanismos possíveis de transmissão. Estudos epidemiológicos sobre a distribuição e associações possíveis quanto a estes episódios. Melhor conhecimento da morbidade destes casos, em particular, e da doença de Chagas na região, em geral (aqui, associar inquéritos clínicos e eletrocardiográficos aos estudos sorológicos de populações). Maior refinamento dos estudos de mortalidade registrada (com análise de autoctonia, tipo de morte, faixa etária, etc.). Isolamento e caracterização de cepas em casos humanos. Estabelecimento de áreas bem caracterizadas para estudos longitudinais de transmissão e evolução clínica da doença, baseadas no inquérito soroepidemiológico. Estudo particular de prevalência e morbidade em populações indígenas. Ensaios de tratamento específico nos casos indicados (agudos, congênito, baixa idade).

Epidemiologia geral, sociedade e ambiente: estudos longitudinais de áreas homogêneas para estabelecimento de perfis de incidência e morbidade (vide acima). Caracterização ambiental das áreas com circulação do parasito (desmatamentos, migrações, tipos de ação antrópica, tipologia habitacional, determinantes macrossociais, etc.). Sensoreamento por satélite, buscando-se identificar as características naturais e antropossociais dos focos de transmissão da doença. Parceria com SIVAM, FUNASA, IBAMA, etc. Entrosamento com os demais países amazônicos com vistas a pesquisa compartida (papel de liderança para o Brasil).

Controle e vigilância: busca de estratégias e técnicas frente à realidade epidemiológica encontrada (itens anteriores). Aprimoramento dos sistemas de hemoscopia para malária com vistas à detecção de casos agudos de doença de Chagas. Centros sentinela para detecção e análise de vetores em alguns pontos estratégicos da região. Ensaios de luta química e manejo da habitação e do ambiente em áreas de domiciliação de vetores. Estudos de prevenção de transmissão oral. Estabelecimento de esquemas regionais de vigilância epidemiológica com base na rede do SUS e com apoio da FUNASA. 